\title{
A corporeidade da mulher Xavante: um movimento da cosmogonia
}

\author{
The corporeality of the Xavante woman: a cosmogony \\ movement
}

Maria Aparecida Rezende ${ }^{1}$

DOI: http://dx.doi.org/10.20435/tellus.v18i37.500

\begin{abstract}
Resumo: O texto tem o objetivo de apresentar de modo sucinto a corporeidade e o movimento da cosmogonia das mulheres da aldeia Pimentel Barbosa. As protagonistas são as mulheres idosas que não conhecem a cultura escolar, mas são guardiãs da cultura do povo Xavante, no texto usando o nome que eles se autodenominam Áuwẽ uptabi (entendimento próximo por povo autêntico e verdadeiro). O questionamento maior é realizado pelas próprias mulheres quando perguntam - por que falam muito da festa dos homens Áuwẽ e não falam das mulheres? É comum leituras extensas em obras da antropologia, da linguística, educação, enfim, vários autores que pesquisaram esse povo fazem abordagens acerca dos rituais masculinos e não colocam as mulheres em evidências. A metodologia usada é parte da tese doutoral, em que o enfoque são elas, mas também informações obtidas por meio das conversas informais e vivências com essas mulheres em outros momentos que não são de pesquisas. As fontes advêm do universo da fenomenologia, Merleau-Ponty $(2009,2006)$, Freire, Astrain e outros autores. O resultado da discussão é o debate de como tem caminhado a questão do diálogo entre povos indígenas e não indígenas no sentido de interculturalidade; como vive esse povo em meio ao contexto cultural de contato não indígena. Assim, o texto vai se desenhando e fazendo uma pintura em paisagem colorida mostrando o universo dessas mulheres, sua relação com o mundo cósmico e com o mundo ocidental.
\end{abstract}

Palavras-chave: corporeidade; interculturalidade; educação; movimento

Abstract: The text aims to briefly present the women's corporeality and the cosmogony movement at the Pimentel Barbosa village. The protagonists are old women that do not know the school culture, but are guardians of the Xavante people culture, in the text using the name they call themselves A'uwẽ uptabi (close understanding by authentic and true people). The biggest question comes from the women themselves when they ask - why do people

${ }^{1}$ Universidade Federal de Mato Grosso (UFMT), Cuiabá, Mato Grosso, Brasil.

Tellus, Campo Grande, MS, ano 18, n. 37, p. 105-119, set./dez. 2018 
talk a lot about the men's party A'uwẽ and do not talk about the women's? It is common to find extensive readings in books of anthropology, linguistics, education, in short, several writers who researched this people wrote about the male rituals and did not put the women in evidence. The methodology used is part of a doctorate thesis, which focus on them, but information was also obtained through informal talks and experiences with these women in other times outside the research. The sources come from the universe of phenomenology, Merleau-Ponty $(2009,2006)$, Freire, Astrain and other authors. The result of the discussion is the debate on how the issue of the dialogue between indigenous and non-indigenous people has moved in the direction of interculturality and how this people lives in a cultural context in contact with non-indigenous people. Thus, the text is drawn and painted in a colorful landscape showing the universe of these women, their relationship with the cosmic and Western world.

Keywords: corporeality; interculturality; education; movement

\section{INTRODUÇÃO}

A tese de doutorado atendeu a uma reivindicação das mulheres Xavante da aldeia Pimentel Barbosa - Terra Indígena Pimentel Barbosa. Ao apresentar o projeto de doutoramento para elas, ele foi reprovado e aceito ao mesmo tempo. Reprovado porque aquele projeto não era o que elas queriam ver na escrita e reivindicado em 1998. O projeto delas era outro, e pediram para eu ficar na aldeia. Qual era então o "objeto" da pesquisa? Qual o objetivo? Qual metodologia? Os dias foram passando e, a cada dia, surgia um convite realizado por várias mulheres idosas, uma ou duas de cada vez. Os espaços e o tempo se modificavam de acordo com a convidante: ao córrego, à roça de mandioca, à construção de farinha, à roça de arroz consorciada com abóbora e batatas. Ir à expedição de coleta de frutas e batatas. Elas demonstraram em suas ações o que o filósofo Merleau-Ponty aponta: somos consciência, e ela está encarnada em nosso corpo, e este não é como descrito na ciência humana - um objeto, e sim humano habitado por uma consciência.

E foi nesse movimento temporal e espacial que a temática foi surgindo, o objetivo aparecendo, a metodologia sendo traçada naqueles caminhos percorridos pelos diversos lugares da aldeia e seu entorno. A predominância da ciência incrustada foi distanciando-se pela efetivada e afetividade daquela construção de projeto, da amizade e reconquista da confiança meio colocada em cheque pela distância dos longos meses de ausência. Um projeto que tomava corpo. Não da 
ciência do ocidente, mas do conhecimento milenar. Uma educação que atravessa o tempo, o espaço e vai se inscrevendo na história e na corporeidade do povo Xavante, que se autodenominam A'uwẽ uptabi. Numa tentativa de interpretação para a língua Portuguesa, seria "somos povo verdadeiro e autêntico". Ao final, a tese ganhou o nome do projeto das mulheres: "A Organização Social e Educativa das Mulheres da Aldeia Pimentel Barbosa - uma etnografia das educadoras piõ A'uwẽ".

A pedido delas, sua vida foi se desenhando e imprimindo nas páginas o que elas queriam ver escrito e fotografado: o trabalho das mulheres para mostrar o quanto elas são importantes em sua sociedade, mas que o waradzu (não indígena) não tem conhecimento e as repudia; não as conhece.

Essas protagonistas foram as inspiradoras desse texto que apresenta como objetivo mostrar a corporeidade da mulher Xavante- $A^{\prime} u$ wẽ em movimento com sua cosmogonia no ritmo de suas vivências. Assim, ao longo do texto, esse movimento vai se revelando e apontando necessidade de um aprofundamento dialógico com o filósofo Merleau-Ponty, Freire, Honneth, Geertz e outros teóricos que podem contribuir nessa discussão.

Espera-se, portanto, que, ao trazer o movimento dessa corporeidade que constitui essas mulheres, idosas, guardiãs dos saberes milenares, as mensagens possam transmitir suas vidas traduzindo seus desejos de comunicar com o externo e com o interno para compreendermos a importância desse conhecimento para as gerações futuras do povo A'uwẽ uptabi.

\section{QUEM SÃO AS MULHERES A'UWẼ UPTABI E QUAIS SÃO SUAS EXPECTATIVAS DE VIDA?}

As mulheres A'uwẽ pertencem ao tronco linguístico macro-jê da família Jê. Vivem na aldeia Pimentel Barbosa da Terra Indígena Pimentel Barbosa. Em 2012, elas tinham entre 55 e pouco mais de 70 anos consideradas as guardiãs da sua história. Seis mulheres îhi (idosas) escreveram essa história por meio de seus corpos, da oralidade e de suas ações. Elas aprenderam, desde o ventre de suas mães, o viver feminino A'uwẽ. Aprenderam as normas, os regulamentos, ou seja, foram educadas para ser mulher. Esse aprendizado durante todo o ciclo educacional ocorre dentro de um contexto e um conjunto de coisas aprovados pela tradição do povo A'uwẽ uptabi. Nesse contexto que se apresenta ao que é nominado de 
cosmogonia, qual seja, todos os aspectos relacionados à sua existência, a formação do mundo A'uwẽ, as diversas concepções do universo das mulheres.

Numa discussão merleaupontyana podemos considerar que, sendo um ser visível no meio de outros seres, móvel, tátil, tocável, sonoro, o corpo é movimento, criador de sentidos relacionado à percepção um acontecimento da corporeidade, da existência.

Nessa discussão, é necessária a compreensão sobre esse corpo. MerleauPonty (2009, p. 21) diz que "Antes da ciência do corpo - que implica a relação com outrem -, a experiência de minha carne como ganga de minha percepção, ensinou-me que a percepção não nasce em qualquer outro lugar, mas emerge no recesso de um corpo". Essa questão nos leva a um refletir, pois o corpo, a corporeidade é mais do que um corpo humano. Isso posto porque a carne de que aborda esse filósofo também não é a carne, parte comestível, e sim outra dimensão mais profunda. Assim o filósofo da fenomenologia existencial afirma que (MERLEAU-PONTY, 2009, p. 128):

Abertura pela carne: os dois lados da folha de meu corpo e os dois lados da folha do mundo visível... É entre esse avesso e esse direito intercalados que há visibilidade. Meu corpo modelo das coisas e as coisas modelo do meu corpo: o corpo ligado por todas as suas partes ao mundo, contra ele - tudo isso quer dizer: o mundo, a carne não como fato ou soma de fatos, mas como lugar de uma inscrição de verdade: o falso arriscado, não anulado.

Nessa direção, observamos que essa carne é o ser em sua profundidade relacionado com o eu no mundo. Isso significa que essa corporeidade não está presa a um corpo humano, mas em liberdade de movimento com o mundo. A visibilidade das coisas, como afirma Merleau-Ponty (2009), está entre o avesso e o direito. A compreensão disso se faz a partir do momento em que me desligo de um corpo inerte, sem movimento. As mulheres A'uwẽ nesse movimento de ser elas mesmas vão se comunicando com todas as coisas que as rodeiam, e as coisas com elas.

O caso da palmeira buriti é um fato que exemplifica essa relação entre a palmeira e elas. Nas coletas do fruto para alimentar suas famílias, elas vão semeando mais buritis pelo caminho. Após ingerir a polpa do fruto, sua semente é jogada e fecundada pelo solo propício para seu desenvolvimento. A semente, em contato com a terra-mãe que a abraça, vai se desenvolvendo em um movimento criando 
corpo. De filha passa a ser mãe dando vida a novas palmeiras em movimento com os pássaros, humanos/A'uwẽ e outros animais que também dependem dessa simbiose para fortalecer a relação da e com a vida.

Nessa condição as mulheres, para além do alimento, também constroem peças para o seu trabalho doméstico. Elas tecem o siõno, espécie de cestos confeccionados a partir das folhas e brotos do buriti, e eles são de diversos tamanhos de acordo com suas necessidades. Esses cestos são usados para transporte de arroz, de mandioca, de frutas, batatas, lenhas, roupas e vasilhas para lavar no córrego e outros usos quando vão a cidade fazer compras. Também esses cestos são usados como "berços" em movimentos que acompanham a corporeidade de suas mães, avós e irmãs ao carregarem os bebês até próximo aos dois anos de vida. É nesse berço que as crianças esperam pacientemente que suas educadoras façam os seus trabalhos. Embalados pelo balanço do corpo em movimento, as crianças adormecem, enquanto isso quem estava carregando está dispensada de cuidados com elas. Assim sendo, o cesto é um instrumento em que as crianças passam longos períodos de suas vidas.

No ritmo de suas vivências, essas mulheres idosas, vão ensinando para as jovens e crianças, desde o ventre de sua mãe, como é educada uma mulher A'uwẽ. Elas não ignoram que vivem em outra dimensão cultural e que essa cultura é dinâmica, mas que elas podem viver os mesmos processos da vida relacionando-se com a educação dos Áuwẽ e com a educação do waradzu (não indígena). Mas elas se preocupam com as seduções externas em que as crianças e jovens

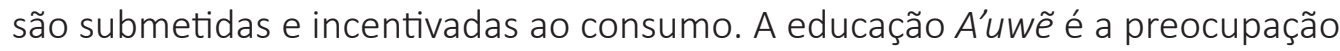
primeira das idosas e dos idosos.

As mulheres idosas da Terra Indígena Pimentel Barbosa sempre se preocuparam com a educação e levar a tradição adiante como mostram (LEEUWENBERG;

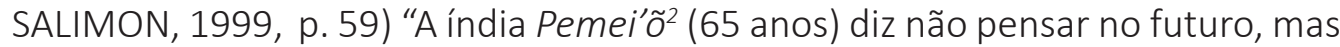
em transmitir tudo que sabe para suas filhas para garantir que seus conhecimentos não se percam com o passar do tempo". Elas ficam mais reclusas na aldeia, saem

\footnotetext{
${ }^{2}$ Essa mulher citada à época pelo autor, era membro da Aldeia Pimentel Barbosa, atualmente ela vive na aldeia Etenhiritipá da Terra Indígena Pimentel Barbosa, aldeia desmembrada por diferenças internas no grupo, ou do modo de vida deles, "políticas internas". Nota retirada da tese de Maria Aparecida Rezende.
} 
quando é estritamente necessário, vão até a cidade para coletar frutas da época, como mangas e outras, bem como para receberem a aposentadoria, ou melhor, acompanharem a pessoa que recebe por elas, seja o esposo, o filho, ou o neto. Dedicam seu tempo ao trabalho na roça, na coleta de frutos e outros alimentos; nos afazeres da casa e no cuidado de suas crianças; também confeccionam os utensílios domésticos trançados com palha de buriti.

A contrariedade e o medo da cultura do waradzu toma corpo no meio de suas crianças, seja homem ou mulher, faz com que as mais velhas se sintam responsáveis em pensar estratégias de ensino que seja mais atraente do que a proximidade com a cultura do outro. Esse modo de educar deve ser compreendido em seu significado profundo como afirma (FREIRE, 2001, p. 12) "aprender e ensinar faz parte da existência humana, histórica e social, como dela fazem parte a criação, a invenção, a linguagem, o amor". Por isso elas criam estratégias dos usos e costumes alimentícios, da língua $A^{\prime} u w e \tilde{e}$, da tonalidade da voz da mulher, dos ritmos de seus corpos ao trabalhar e participar dos seus ritos, sejam festivos e sagrados ${ }^{3}$. Entre os Xavante as festas ocorrem por variados motivos, dentre eles, cânticos para a cura de doentes, rituais de nominação, de formação do homem e mulher e diversos rituais que fazem parte dos espaços e tempo festivos desse povo. Esses momentos são usados pelas mulheres como elementos educativos, mas a peça fundamental é o amor e a clareza do que elas buscam nessa educação.

Em linhas gerais, a mulher Xavante, ao longo da história, tem demonstrado sua força na educação e na sobrevivência do seu grupo. Exímias coletoras, também são agricultoras que trabalham em suas pequenas roças para prover um mínimo de alimento como arroz, feijão, milho (específico do povo Xavante) e outros alimentos.

Enquanto educam seus filhos e filhas, netos e netas elas vão costurando a posição da identidade que cada ser ocupa no seio dessa sociedade educadora, identidade essa construída junto com sua convivência social e no contexto sociocultural, político e econômico.

\footnotetext{
${ }^{3}$ Recentemente, o filósofo e antropólogo italiano Massimo Canevacci insistia que "o sagrado não deveria ser confundido com a religião" Veja IHU On Line. 07 maio 2012: Disponível em: <http:// migre.me/aWKIx>. Há outros sagrados na vida humana, o território, os velhos, as crianças, as fontes de água, as plantas, o corpo, o alimento, o amor. Nota retirada da tese de Maria Aparecida Rezende.
} 
Vários são os espaços educativos e o Warã é um dos espaços que auxiliam na efetivação dessa educação. O lugar onde se discutem as normas e regras não cumpridas e o caminhar da comunidade coletivamente. A participação das muIheres se efetiva de outra forma, já que não é permitida sua presença física. Em casa, seus esposos e demais homens adultos que acompanham o Warã tomam as opiniões das mulheres para si e levam ao debate masculino. Sabendo de toda a discussão que ocorre nesses momentos é costume delas esperar o final da reunião do período da manhã para iniciarem o dia de trabalho, o que ocorre no máximo até as sete horas, e cada coletivo de pessoas já inicia seus trabalhos.

A maior preocupação das velhas A'uwẽ é a de que as crianças e as jovens mulheres $A^{\prime} u$ wẽ deixem de reviver esse cotidiano que sustenta esse povo: a prática dos ritos, a crença nos mitos, as danças ritualísticas carregadas de significações, a coleta das batatas nativas e outros alimentos, seja no cerrado ou na mata. Enfim, tudo isso requer uma repetição de tarefas, cada dia diferente em seu modo de acontecer, pois cada dia é singular em suas vidas, o modo de observar os exemplos para que a cultura seja continuada ao longo da vida futura do povo Xavante.

A centralidade de suas vidas parece estar no trabalho. É por meio dele que elas se conectam com a terra, seus frutos, com as matas e cerrados, rios e todo o trabalho da construção das roças, da vida alimentar e da vida espiritual e, com isso, demarcando espaços e tempos educativos ao realizar o trabalho de responsabilidade da mulher.

A pesquisa foi um alicerce para o conhecimento construído com as muIheres. Mesmo com as vivências anteriores, não foi possível perceber o mundo delas repleto de conhecimentos para serem ensinados não somente aos A'uwẽ, mas a quem quisesse e tivesse interesse de aprender as lições daquele cotidiano construído de aprendizagens.

\footnotetext{
${ }^{4}$ Entendo o Warã como uma assembleia masculina, espaço usado no centro da aldeia para planejar e avaliar as atividades desenvolvidas no cotidiano da aldeia. É um espaço de decisões políticas, em que conflitos e tensões são resolvidos ali mesmo, com tempo de iniciar [antes do sol nascer pelas $5 \mathrm{~h}$ e a outra depois do pôr do sol, das $18 \mathrm{~h}$ às $19 \mathrm{~h}]$. Não existe um tempo determinado para o término da reunião, depende do número de assuntos e de sua complexidade. As mulheres Xavante não podem participar, a mim foi liberado para contar o que eu iria fazer. É importante acrescentar que não existe um móvel coberto, mas sim ao relento, sem casa, mas todos sabem o lugar do Warã ele fica naquele lugar, sem variação.
} 
Um cotidiano que foi fotografado por minhas retinas e depositado em minha memória acerca do mundo educacional dessas mulheres. A cultura como peça importante nesse entendimento e nessa compreensão de ensino e aprendizagem. O conceito de cultura compreendido por antropólogos e alargado pelo filósofo da educação que se inspira em Geertz (1989) ao afirmar que (PASSOS, 2003, p. 182)

A cultura responde à necessidade inapelável dos homens de, para sobreviverem como tais, comunicarem-se uns com os outros. Não é uma entidade física, mas ideação mediada pelo simbólico, suporte da constelação de significados criados pelos humanos, a um só tempo constituída por eles e constituinte. Expressa uma teia de significados universais mediados por sentidos singulares.

Para ele a cultura passa a ser encarnada nas pessoas e tem um sentido inédito e disponível do seu agrupamento social; a cultura é a peça chave que confecciona o ser humano, que faz dele o seu particular, a sua singularidade circunscrita na universalidade humana.

Essa educação que ajuda na construção da pessoa, grafada por Brandão (1985, p. 7-26) ao afirmar que ninguém escapa dela, tamanha sua importância.

Ninguém escapa da educação: todos nós envolvemos pedaços da vida com ela. Não há uma forma única de educação e nem modelo e a escola não é o único lugar onde a educação acontece e talvez nem seja a melhor. $O$ professor profissional não é seu único praticante. A educação existe em cada povo ou entre povos que se encontram. A educação é uma fração do modo de vida dos grupos sociais que a criam, recriam, entre tantas outras invenções de sua cultura. A educação aprende com o homem a continuar o trabalho da vida. Em uma etnia, a sabedoria acumulada do grupo social não "dá aulas" e os alunos que são todos os que aprendem, não aprendem na escola. As pessoas convivem umas com as outras e o saber flui, pelos atos de quem sabe-e-faz, para quem não-sabe-e-aprende. A educação aparece sempre que surgem formas sociais de condução e controle da aventura de ensinar-e-aprender.

Ao afirmar que ninguém escapa da educação, Brandão sabiamente descreve o que seria "educação". Muitas pessoas tentam definir essa palavra. Ela parece simples, mas, para explicar o seu entorno e o que ela representa, é preciso olhar as dimensões sociais, políticas e culturais e, ao mesmo tempo, cada núcleo familiar ou de cada povo que a vive. A educação da criança feminina A'uwẽ segue os passos e a caminhada que fazem as mulheres mais velhas do seu grupo familiar. 
Também, se aprende com a comunidade. No caso das mulheres deste estudo, elas dizem a "palavra" num sentido freireano, mas daquela forma que está gravada em sua memória, e, como uma boa guardiã, as palavras não acompanham o código escrito, mas sim o som de sua língua e de todas as lições dadas e recebidas ao longo dos seus anos. A educação é contínua.

Mas é importante dizer que essa educação, assim como a cultura, não é estática e caminha porque tem vida. Ao longo dos anos, essa educação vai se modificando, acompanhando a existência e a realidade de cada época. É por isso, por essa adaptação é que a educação dos povos indígenas vem se fazendo ao longo dos anos, apesar dos mais de 500 anos sob a égide de uma cultura dominante, eles seguem com seu jeito de ser e de viver.

Vale reafirmar que esse texto é um acumulado de anotações do caderno de campo não somente de parte da pesquisa doutoral, mas de outras vivências por meio de visitas afetivas, um relato etnográfico, observações dos muitos momentos vividos entre os A'uwẽ.

A compreensão educativa das mulheres A'uwẽ foi possível também por meio da narrativa de um mito Wasi Wasu'u registrado na tese de Arthur (EID, 2002) primordial para um equívoco de uma leitura ligeira acerca do mundo dessas mulheres de que são submissas aos homens. O mito auxilia a desfazer esse mal-entendido. Os homens dessa aldeia, em especial os mais velhos, buscam compreender desse mito o tamanho poder que tinha a Wasi Wasu'u (a mulher ancestral que vivia no höiwa - céu). O mito deixa transparecer a pintura de nominação que a "estrela" vem vestida, mas não fala do longo ritual que demanda dessa festa e que é comentada por alguns antropólogos dentre eles, Aracy Lopes da Silva, (1986), incluindo o sentido do casamento para a Sociedade Xavante.

O cotidiano dessas mulheres continuará. Suas expectativas, embora reclamem seus receios, é a de que a cultura poderá sofrer transformações, mas a educação A'uwẽ uptabi estará sempre forte. Oxalá, suas vozes ecoem além dos buritizais, da flora e fauna que amam, de todos os tipos de vegetação - mata, cerrado, campo, Ihes deem vida e lhes ofereçam a continuidade e o fortalecimento da sua cultura e seu modo de ser e viver. 


\section{CONSIDERAÇÕES REFLETIDAS NA CORPOREIDADE DESSAS MULHERES E O DIÁLOGO COM A CULTURA OCIDENTAL}

Aqui a consciência está encarnada em um corpo e nosso corpo não é como descrito na ciência humana: um objeto e, sim, humano habitado e inanimado por uma consciência. O tempo nos faz. Somos conscientes, nascemos, vivemos e morremos. Seres espaciais que somos porque vivemos no mundo e este é fruto de lugares. A fenomenologia ao dialogar com o mundo afirma que o homem, a mulher é um grande projeto a ser construído, e isso se faz a partir de suas experiências vividas no e com o mundo. E esse mundo é tempo.

O mundo feminino das mulheres em questão é o tempo/trabalho; tempo/ amor; tempo/educador; tempo/ensino; tempo/aprendizagem; tempo/persistente; tempo/resistente. Viver para Merleau-Ponty é, portanto, estar no mundo, e a percepção é essa relação do meu corpo no mundo. Com isso confirmamos com ele que, ao descrevermos essa realidade do mundo feminino Áuwẽ, ela ocorre como se apresenta, pois nossa percepção é particular, imperfeita e inacabada.

No início do texto, foi situado o contexto desse diálogo ao abordar a pesquisa que deu origem a ele. Posteriormente foi desenvolvido assunto interligado a corporeidade dessas mulheres em seus movimentos cosmogônicos. Suas vivências são contextos que contornam seus medos e anseios. O cotidiano revela suas angústias de construir alternativas para minimizar os encantamentos que os jovens, as jovens e crianças vão adquirindo pela cultura do waradzu (não indígena).

A cultura dos não indígenas tem chegado aos povos indígenas sem pedir licença para entrar. Ela chega de todos os lados. Ela entra com eles em seus espaços educativos, entra com a escola, entra por meio da TV, internet e outras formas de entradas sem pedir licença. A Constituição Federal de 1998 foi uma conquista dos povos indígenas e seus aliados não indígenas, no sentido de garantir direitos que exigem respeito com seu modo de ser e viver. A partir daí, a preocupação com essas prerrogativas foram crescendo, e o pedido dos povos indígenas se intensificando, e originou-se a Educação Escolar Indígena.

A Educação Escolar Indígena nada mais é do que um esforço de mudança para que a cultura escolar não detone a cultura indígena, mas que ambas se tornem aliadas nos processos de ensino e aprendizado para a formação de vida e pessoal. 
O outro conceito interligado a este aparece com o nome de interculturalidade que é uma relevância de contextos culturais. Astrain (2010, p. 58) afirma:

A interculturalidade é uma nova e cada vez mais nítida tomada de consciência a respeito de que todas as culturas estão em um processo de gestação de seus próprios universos de sentido e, ainda, sem a possibilidade teórica de subsumir completamente o outro no meu sistema de interpretação.

Os povos indígenas têm demonstrado, ao longo dos anos de dominação da sociedade ocidental, facilidade para o diálogo entre as culturas. Esse sempre foi o desejo deles, até porque viviam e vivem massacrados pela cultura que sempre se considerou superior a todas as outras diversidades culturais. O sistema capitalista impõe, por meio da sua histórica colonização, a relação vertical de sua cultura em relação a todas as outras. O seu sentido de interpretação caminhou e caminha conforme a sua necessidade de continuar dominando.

Esse mesmo autor (ASTRAIN, 2010, p. 58-9) descreve sobre a necessidade da maturidade da ideia de interculturalidade discutindo um reposicionamento da relação de uma cultura com as outras fazendo três indicações:

A primeira é o pressuposto do prefixo inter - existente, em outros usos: internacional, intervalo, [...] pois remete sempre a um tipo de contato entre uma ou mais culturas. A interculturalidade é, nesse sentido, uma categoria que permite dar conta do modo de contato - que pode ser simétrico ou assimétrico - das culturas. [...] em segundo lugar, a interculturalidade pode ser concebida também a partir dos diferentes espaços de poder do conhecimento. [...] $\mathrm{O}$ terceiro aspecto em relação ao conceito de interculturalidade reporta ao fato de que ele não pode estar separado de processos de auto - e de hetero-reconhecimento entre culturas diversas - culturas nacionais, populares e étnicas.

A primeira compreensão, de acordo com o autor (ASTRAIN, 2010), inter trata-se da superação de algumas categorias como mestiçagens, aculturação e transculturação que supõe indício de absorção evolutiva. A segunda chama a atenção para o perigo da interculturalidade fazer sombra para a primazia de uma cultura sobre a outra. Pensar uma interculturalidade ligada ao respeito, ao diálogo e os ensinos e aprendizados juntos. E por fim, o terceiro aspecto ele aborda a necessidade da interligação do processo de auto e hetero-reconhecimento que conduz a discussão às formas de reconhecimento das identidades culturais. 
O reconhecimento é um conceito muito debatido e que Honneth traz, em seu bojo, o amor, o direito e a solidariedade (PIZZI, 2017, p. 170); seguindo a adoção de Honneth afirma que o reconhecimento pode ser referido em três esferas distintas:

a) em primer lugar, una gramática de la razón que permita la apertura a nuevas experiências, es decir, de la capacidad de razón filosófica em reconocer la diferencia; b) em segundo, su posibilidad de reconocer el "filosofar" latino-americano; c) y em tercer lugar, reconocer el cambio geo-cultural, cuyo nuevo eje de la tradición occidental pueda interconectar las tradiciones iber-afro-indigena latinoamericana.

Sem o conhecer, o termo reconhecimento é tudo o que as mulheres $A^{\prime} u w \tilde{e}$ pediram e esperam da sociedade, das pessoas não indígenas que vivem no entorno de sua sociedade, mas que não aceitam outra educação com valores e razões diferenciadas de ser e viver. Querem ser reconhecidas como gente, como pessoas que trabalham, que vivem e que têm o direito de ser respeitadas em suas diferenças. O fato de viver diferente não quer dizer que são inferiores. Elas sentem isso da sociedade ocidental em relação à sociedade dos A'uwẽ.

A filosofia de vida desse povo é o de dialogar com todos os seres vivos. É o de ter espaço para todos os viventes do planeta e não dar a supremacia aos seres humanos. Todos querem viver e devem aprender e ensinar juntos. É esse "interconectar" com todos e todas que elas vêm solicitando sempre. Isso não quer dizer que seja uma súplica, mas um chamado à coerência, política social digna e ética com a diversidade cultural, linguística e educacional entre os seres humanos e não humanos, mas todos merecem respeito à vida. Isso, segundo elas, só é possível se houver amor entre todos e todas. Essa é a verdadeira interculturalidade.

O filósofo Astrain (2010, p. 64) vai mais longe nessa discussão propondo uma ética intercultural. Esta, para ele "é como procura deste espaço de compreensão entre-culturas, pressupõe uma opção pela discursividade, capaz de validar um procedimento definidor das regras, a partir de uma modalidade contextual". Mas isso no sentido de meta-ético que possibilite um diálogo respeitador, que assegure os direitos de viver dignamente sem ser oprimido.

Ao terminar sua obra (ASTRAIN, 2010, p. 157), faz uma discussão interessante para esse diálogo 
A ética que assume a discussão dos conflitos a partir dos próprios contextos culturais - onde existe tensão entre a homogeneidade a heterogeneidade do processo sociocultural e político - sustenta que eles são fonte de novas virtualidades da ação. [...] o apelo à produtividade semântica dos contextos nos conduz a interpretar, de outra forma, tanto impacto dos novos valores associados às pautas de consumo, como ao deslocamento dos antigos valores que regulavam os diversos e tradicionais mundos de vida. [...], nos leva a compreender as sendas de um 'sentido' associado às formas criativas e inovadoras, as quais dão conta de outras situações culturais e morais que afetam os sujeitos e às comunidades de vida, a reconhecer a lenta e fatigosa marcha a favor de uma universalização requerida para construir uma verdadeira humanidade.

Essa finalização de texto de Astrain é a chave necessária para ir amarrando a questão da corporeidade feminina $A^{\prime} u$ wẽ e o movimento de sua vivência no contexto cultural em que vive a mulher A'uwẽ. É provocando o conflito entre o consumo da cultura ocidental pelas jovens e crianças feminina, que as mulheres idosas vão trilhando o caminho em busca de alternativas para revitalizar essa força cultural A'uwẽ. Isso indica que, ao afirmar que a juventude não está realizando a contento sua cultura, elas provocam desafios e sabem que surtem resultados e, com isso, vão fortalecendo seu modo de educar Áuwẽ uptabi (povo autêntico e verdadeiro) e garantindo, ainda que com medo de que isso se perca ao longo dos anos, a sobrevivência linguística, cultural, alimentar e a manutenção de todos os rituais $A^{\prime} u w e \tilde{\text {. }}$

As mulheres são a sustentabilidade da vida do povo A'uwẽ. Enquanto a relação de contato vai se estreitando, elas vão construindo novas estratégias de sobrevivência linguística, alimentar e ritualística próprio do seu mundo Áuwẽ uptabi. Esses três aspectos merecem destaques: a) a língua é um modo de liberdade de expressão; comunicação com a espiritualidade, desde seus sentidos polissêmicos à sua tonalidade de voz. A língua é a riqueza da comunicação entre todas as pessoas dessa etnia; b) a alimentação da tradição desse povo é que assegura e confirma a saúde e a propagação de diversas espécies e uma delas já citada ao longo desse texto, como rainha-mãe da vida desse povo: a palmeira do buriti. Seus frutos alimentam e dão vida; suas folhas constroem utensílios domésticos que são usados para a vida como dormir (esteiras) transporte (carne para festa de casamento, lenha, mandioca, diversidade de coletas, seja de frutas ou raízes, de 
crianças e outros); c) os rituais estão interligados aos dois aspectos anteriores: dão vida para a comunidade em festa. Marca a história, a temporalidade e o tempo e espaço do modo de ser e viver. Todos os ritos são valores concebidos ainda no ventre e dão sequência até o final do ciclo de vida.

Tudo isso é a ética que conduz essas mulheres à (re)elaboração dos modos de sustentar a vida dos A'uwẽ. Suas ações são voltadas para o bem viver do seu povo levando em conta os contextos em que estão exprimidos, dos impactos violentos do contato direto e próximo de outra forma de viver que não respeita seus modos de vida. Procuram associar formas criativas e inovadoras para dar conta de "driblar" esses contextos culturais que vêm ameaçando sua cultura, sua pedagogia, enfim todo seu sistema educacional que fazem do homem e da mulher A'uwẽ serem diferentes, éticos, solidários, dialogadores e com o desejo de trazer para perto esse elo de vida, que podem enriquecer as culturas diferentes sem hierarquizar essa relação, a interculturalidade entre as sociedades.

Em todas as marcas que sinalizam sobrevivência e sustentabilidade, as mulheres marcam presença com seus corpos, corporeidades tonificando a vida. Uma vida elaborada, sistematizada e efetivada pela preocupação com o tempo e espaço do seu desenvolvimento e de se manter Áuwẽ uptabi.

\section{REFERÊNCIAS}

ASTRAIN, Ricardo Salas. Ética intercultural: (re)leituras do pensamento Latino-Americano. Tradução e revisão de Dilnéia Tavares do Couto e Jovino Pizzi. São Leopoldo: Nova Harmonia, 2010.

BRANDÃO, Carlos Rodrigues. O que é educação. São Paulo: Editora Brasiliense, 1985.

EID, Arthur Shaker Fauzi. Romhõsi'wai hawi rowa'õno re ihoimana mono: a criação do mundo segundo os velhos narradores Xavante. 2002. Tese (Doutorado em Ciências Sociais) - Universidade Estadual de Campinas (UNICAMP), Campinas, 2002.

FREIRE, Paulo. Educação como prática da liberdade. 24. Ed. Rio de Janeiro: Paz e Terra, 2001.

GEERTZ, Cliford. A interpretação das culturas. Rio de Janeiro: Editoria LTC, 1989.

LEEUWENBERG, Frans; SALIMON, Mário. Os Xavantes na balança das civilizações. Rio de Janeiro, 1999. 
MERLEAU-PONTY, M. O visível e o invisível. Tradução de José Artur Gianotti e Armando Mora d’Oliveira. São Paulo: Perspectiva, 2009.

. Fenomenologia da percepção. 3. ed. São Paulo: Martins Fontes, 2006.

PASSOS, Luiz Augusto. Currículo, tempo e cultura. 2003. Tese (Doutorado em Educação) - Pontifícia Universidade Católica de São Paulo (PUC), São Paulo, 2003.

PIZZI, Jovino. Esfera del reconocimiento: hacia uma perspectiva ibero-afro-indígena latino-americana. In: SAUERWALD, Gregor; ASTRAIN, Ricardo Salas (Ed.). La cuestión del reconocimiento em América Latina: perspectivas y problemas de la teoria políticosocial de Axel Honneth. 2. ed. Zürich: Editora LIT; VERLAG GmbH \& Co. KG. Wien, Zweigniederlassung, 2017. (Série Discursos Germano-Iberoamericanos).

SILVA, Aracy Lopes da. Nomes e amigos: da prática Xavante a uma reflexão sobre os Jê. São Paulo: FFLCH/USP, 1986.

\section{Sobre a autora:}

Maria Aparecida Rezende: Professora do Programa de Pós-Graduação em Educação (PPGE/UFMT). Possui graduação em Pedagogia pela Universidade do Estado de Mato Grosso, Especialista em Teorias e Métodos da Antropologia e Mestrado em Educação pela Universidade Federal de Mato Grosso. Doutora pela Universidade Federal de Mato Grosso. Atualmente é professora da Universidade Federal de Mato Grosso, Departamento de Teorias e Fundamentos da Educação. E-mail: rezemelo@gmail.com 
